\title{
Light and the Aesthetics of Perception
}

\author{
Carlo Volf
}

\begin{abstract}
Light seems to be a very changeable size in our build environment. Being an immaterial building stone, light takes a very liquid shape in our design-vocabulary. It consists of an invisible material - photons - and therefore it takes no specific form in itself but is only articulated through the meeting with form. Therefore, since form has been the major theme for the aesthetics up until now, giving form to light is a complex and challenging task and reducing it to Lux and measurable numbers only an escape from facing what is actually perceived. In this way light seems to suffer from what can be called the dichotomy between the aesthetics of the objects and the aesthetics of the perception - as stated by Boehme. To improve practice this article conducts a study of our perception, focusing more on the effects of light and less on the physical light (lux). By doing so the article tries to give a better understanding of the differences of the regional lighting cultures and the influences creating the differences. The article tries to establish a link between the regional daylight and the use of artificial lighting, showing that daylight, as a background, along with our perception, are determinant factors for how the artificial lighting and the brightness of the room is perceived. The article hereby suggests that light is not an absolute factor. This means the end of the dichotomy between daylight and artificial light - often expressed by artificial light replacing daylight - instead this article tries to establish a dialogue between the daylight and the artificial lighting. The article describes how light - this intangible building block - can become a more workable size in the aesthetic and architectural practice of today.

KEYWORDS Aesthetic experience, light, atmosphere, space, architecture
\end{abstract}

Aesthetics is a study of the interaction of our senses with our emotions, in short, our taste. A study of our most important sense, the vision, and the influence of the interaction between daylight and artificial light on our vision is of great importance to a deeper understanding of aesthetics. This essay will reveal two major factors of importance; on the one hand, the regional differences, and on the other hand, an insight into our vision and the influence of our vision on what is being seen. Linking these two factors together, this article will give an answer to this fundamental question: Why do Scandinavian countries prefer a warmer artificial light while southern countries use a cooler lighting? This investigation is of importance to aesthetics, as it shows that aesthetics is not an absolute, global phenomenon, but is more likely to be considered a regional phenomenon. Mona Lisa in Paris is not the same as Mona Lisa in Copenhagen. This paper argues against the existing dislocation of light and the separation of light from form in order to create a more human-ecological point of departure for future architecture. 


\section{Introduction}

Lighting belongs to the new aesthetics as described by Gernot Boehme. Light is an everyday aesthetic that surrounds us and forms a background for our lives. Boehme says, "I believe, bringing me to my fourth thesis, that architects and designers of our time can't learn a lot from the theory of aesthetics, on the other hand I believe that aesthetic theory can learn a lot from the practice."1

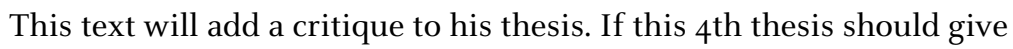
meaning, practice needs to be untied from the leashes that tie it to a functionalistic regime. Since "Mechanization took command"2 many things have changed, and functionalism has reduced light into measurable figures in the Western World in the attempt to produce and plan the best physical environment for human beings. But this has been a poor attempt, reducing experience and atmosphere to zero-value and neglecting the emotional wellbeing of the inhabitants in our built environment.

That aesthetic theory can learn a lot from practice is therefore not a convincing thesis for the building practice in Denmark today, or anywhere else in the industrialized World, for that matter. Working in practice with artificial lighting often means adding quantities of light to a building instead of adding qualities of light to the atmosphere. I often feel that there is a missing link between the building and the light, to improve the aesthetic conditions light should be linked to architecture - creating an architecture as a function of light. That is an architecture where form articulates light and light relates to the room. I will not exclude the overall possibility that aesthetic theory can learn a lot from practice, but dealing with light, practice seems to be submitted to a functionalist way of thinking, where light is added in quanta giving the atmosphere a second rate status, reducing the atmosphere, so to say, "as a function of the function." From a functional point of view, vision is dependent on sufficient amounts of light required for seeing, e.g. reading a book, welding a software part, etc. But this method of thinking deals with a dislocated environment, separated from its surrounding environments. In this sense - leaving all other factors out of the equation - this way of thinking reduces light to a measurable factor, but also a factor that is blind towards the actual experience - and therefore often misleading.

This exclusion of the environment dates back to Adolf Loos' Ornament and Crime and his 30-year struggle against eclecticism. But as Chombart de Lauwe later writes: "By limiting the meaning of the word functionalism - giving the word a far too narrow and technical meaning - any individual freedom was suppressed as if it was all about providing a 
shelter for rabbits or mice rather than for humans." ${ }^{3}$ The fight against the ornament was primarily based on a consensus of fighting for a better world. If only the symbol of evil - the ornament - was exterminated, all evil would perish with it and a new international architecture would emerge; an architecture which in itself would be good if only it refused to use ornament. Of course this did not happen. Instead, we got clean, white rooms stripped of all reflecting and shaping surfaces; an empty holster to be filled with only light as its decoration. But light without form is the same as form without light. So we need to relocate light and continue this debate, as well as to question this development in order to bring us onto a more sustainable course, where interplay between daylight and electrical light, between light and form is examined further.

From a human-ecological point of view, light is only visible because of darkness. If everything is illuminated equally, then we might as well be blind or blinded. Generally, we find ourselves surrounded by more and more artificial light. We see it today in the cities, where focus on "Dark Skies" attempts to limit the amount of artificial light we emit out into space. This light is preventing us from seeing a starry night. We see it when we are driving cars in full daylight with the lights on. This is apparently based on the fact that always driving with the lights on is more secure, which is something that cannot be justified from a professional lighting point of view. Have we gone too far in our artificial and excited use of artificial light, so that we are incapable of even seeing it? Are we quite literally - blinded by light?

\section{A Ground Zero}

Often the dichotomy between daylight and artificial light relates to another dichotomy: Nature versus technology. Sigfried Giedion traces this dichotomy back to Rousseau's time. The contradiction between nature and culture is established along with the rising industrialization in the 18th century. And today, with culture being increasingly based on technology, the contradiction seems to be one between nature and technology. Modern architecture developed after World War I, as a result of social and political revolutions, and driven by technological and engineering developments of new cheap building materials, such as steel, glass, and machinery. These developments resulted in a new way of dealing with daylight. The Crystal Palace by Joseph Paxton at the Great Exhibition of 1851 in London is one of the earliest examples of a new architecture of glass and light. This created a new aesthetic of openness, light, and a healthy and clean physical environment. This healthy and democratic 
architecture has played a major role in 2oth century architecture, bringing light into the buildings - and, as we shall see later, forcing a new way of articulating light - building deeper, with lower room-heights and using UV-filtered and colored glass to protect against overheating, accentuating the use of another kind of light - namely the electrical light.

Until the end of the 19th century no efficient artificial lighting was available, the built environment relied upon the natural existing daylight and light from fire, petroleum, etc. In 1879 Thomas Alvin Edison patented the incandescent bulb and started a network of power-suppliers for electricity worldwide, making it possible to bring a soot-free, safe, and healthy source of light into buildings. Developing fast, electrical lighting and illumination becomes one of the main attractions in the Fin de Siècle architecture. Artificial lighting plays a major role in the industrialization, creating an improved visual environment, so to say, "prolonging the day." Perhaps electric lighting expanded so quickly, because it constituted one of the founding stones of industrialization. There is no doubt that it has an enormous impact on our productivity and on both our physical and psychological development and behavior - making it possible to build larger buildings and creating longer working hours.

However, this success of the electrical lighting has not only had beneficial effects, it has also proven to have some drawbacks. One of these drawbacks is the neglect of the use of daylight - along with a neglect of nature itself. This may seem odd, daylight being considered a very precious factor in the built environment in Scandinavia, in fact in all modernist architecture. But it is nonetheless the rule rather than the exception that the light in modernistic buildings is transported into the room without any articulation, reflection, or optical efficiency. Let me elaborate on this: Light in itself is invisible to the eye, it is only reflected light that is visible to the eye - and therefore only the meeting of light and form is what determines the optical efficiency. Glass and electric lighting do not in itself provide an experience of brightness. Instead, what we have is a sense of brightness and of transparency, based on the presence of so much glass. But actually it provides reduced optical conditions for the eye. As someone once said to me: "During the day I shield the daylight, daylight annoys me, especially when I look directly at the windows." Glare from the windows causes a feeling of a dim and gloomy lighting in the daytime; all focus seems to be outside the building, not inside. Much of contemporary architecture today is like this, squeezed and concentrated, often located on expensive square meters with many floors. But of what help are all the glass facades, when a low room height 
or a deep-plan building is reducing the natural skylight and the amount of daylight in the room?

Walking into an average deep-plan office you have curtain-wall glass on the façade providing a large view, reducing the feeling of a border between indoor-outdoor. However well-planned and beautifully articulated, this curtain-wall glass provides only little reflection and articulation of daylight inside the building. Look at the reflecting surfaces adjacent to the glass: Carpets are often dark for cleaning purpose, no details around the windows, no windowsills. Actually, the sills are often dark so that you focus on the view outside - framed by the window. Was it not for electrical light, it would be an unpleasant experience working in this room, because the contrast between daylight and darkness is too large and you see only silhouettes of persons in the room, which in turn fosters a gloomy atmosphere.

In this way the electrical lighting causes a negligence of daylight. The electric lighting is the excuse for building deeper room-depths with lower room-heights and lower daylight factors, leaving the electric light on all day. However, it was not always like this. Ventilation along with electrical lights - and medicine - have been the driving powers for reducing this room-height to the minimum of 2.5 meters today. With modernist architecture engaging with technology since the 1920-30, both ventilation and electrical lighting became a common mechanization of the building, replacing the tall but expensive 3.0-meter ceiling heights and reducing the window-height. As a result, the word "window" loses its original meaning: wind and ow - wind and eye - fresh air and light.

Between 1930 and 1950 almost 95 percent of all electricity in Denmark was used for lighting. ${ }^{4}$ In fact, the bill for electricity was called a light-bill. At this time there was a limited access to electricity, and electricity was quite expensive. From the 1950 os and up the power-supply was improved and the electricity costs were stepwise reduced. Hence, a big leap is observed from the early 1960s, where both the use of electricity and the available electric equipment doubled within a short period of five years. The following reductions in electricity costs only accelerated the use of more electricity in this period, and what is very symptomatic for this change is the exceeding use of artificial lighting in buildings. In Denmark a final step further away from nature and natural daylight was taken in 1977 with a new building legislation (BR77). Due to the energy crisis, the window area was reduced to 15 percent of the wall-area. This meant that heating energy was saved, but more electrical lighting was required. In reality, making the people more dependent on electrical lighting and less 
dependent on daylight, thereby creating a new building-culture in Denmark - this being a Ground Zero for the lighting in Denmark.

So, all in all, light seems to be a very changeable size.

\section{How to move on from a Ground Zero?}

Why do we need to bring light out of this shadow of functionalism? Because we are forced to do so. We are in a situation where we need to reduce our consumption of artificial lighting, and, this being said, we need to use existing daylight. In short, we need to use light more intelligently and to look more closely at the interaction between daylight and artificial light. Not only for the sake of the environment but also for the sake of our general wellbeing, when we keep in mind that we spend most of our time - up to 90 percent $^{5}$ - in an indoor environment. To improve the chances for practice to create a better environment, let us in the following have a closer study at two factors of importance: (1) the vision and (2) the use of regional lighting conditions.

(1) Vision always adjusts to a given light-level, and it is only able to perceive momentary differences in brightness. At a given time the eye can approximately distinguish up to 20 different lighting intensities. This makes seeing a relative sense - not an absolute sense - and a momentary sense, due to the inability of the eye to remember absolute brightness and color.

That is why light is a changeable size. In the 1930s in Denmark there was a standard saying that 30 Lux on one's desk was sufficient for reading. But today in Denmark it is 400 Lux and in Sweden 500 Lux. In the future, engineers plan for even more Lux - I recently heard 1.200 Lux! This is of course a result of technical developments, but increasing the level to 1.200 Lux will not solve a problem of our perception of brightness nor of darkness, as light is a relative factor. The mere use of more light will therefore not result in a better physical environment.

Let me flesh this out in an example: In Aarhus I have passed through a certain passageway hundreds of times over the years and found the existing electrical lighting in these passages being very sufficient and very well-designed. But then, this autumn, when I returned one evening, a new passageway had been built and added to the existing one prolonging it through to another building complex. The new lighting in this new corridor all of a sudden made the existing passage look gloomy and insufficiently lit, appearing completely different. Though it had not changed at all! This explains the following question: Why does our physical lighting environment change from 30 Lux to 1.000 Lux? The answer to this 
question is that we do not observe this change. As the previous Lord Mayor of Copenhagen Ritt Bjerregaard recently said at Earth Hour 2009: "We get used to the light - the more light we use the more light we need! Now to argue to what extend a recent amount of light (Lux) is, is a very interesting and complex matter. But this observation means for sure that there seems to be no absolute figures, no foundation for absolutism in the case of lighting!"

The human vision is a quite complex matter, also when it comes to distinguishing color. Electrical light appears warmer on a background of daylight, as daylight influences both the experience of brightness and color. The electrical light is like "an artificial sunbeam" striking the room and creating bright and warm colors on the faces we see. Therefore we use artificial light as a way of providing artificial sunshine in our environment. We do not use artificial light only as a mean of getting more light but also of getting warmer light! To explain this further we need to talk about the Purkinje-effect, or the relationship between the photopic day vision and the scotopic night vision. This effect describes how the relative sensations for various colors alter as the brightness values are reduced to lower intensities. The Purkinje effect operates only within the eye, creating this change of color by changing from day vision to night vision. For example, a reddish purple will be seen to vary from reddish purple to a more blue violet. Sensitivity to color changes along with the intensity of the light, from a yellow-green peak-sensitivity (555 nm) and to a more blue-green peak-sensitivity $(507 \mathrm{~nm})$, this means that we see e.g. warm colors in another way at night - as more "white".

This could be the answer to the initial question: Why do people in Scandinavia tend to like a warm electrical light compared to the cool daylight? New lighting technologies like LED and CFL make it possible to change to any color you would ever like, breaking the existing restricting technology of the incandescent bulb with its characteristic warm color ( $\mathrm{K}$ 2700). Yet we do not observe any change in preference - actually the new technology is only miming the old incandescent light color.

So why this warm color? Because it evokes a feeling of an electric "sunbeam"? As human beings we have developed a unique color vision. Color vision defined as: The capability of discriminating lights (scattered light as well as light sources) on the basis of the spectral content of light, even when those lights are of equal subjective brightness. Now picture the rainbow: What you see appearing as discrete bands of color is not a physical phenomenon; it is not out there arisen from the radiation in the sky. If you measure the radiation with a spectrophotometer, you will find 
that the wavelength of maximum intensity, as a function of the radial distance across the rainbow, decreases smoothly and monotonically from the outside to the inside of the bow. The apparent discreteness is an artifact of our photo-pigments (chromophore and opsin) and the neural processing of our photoreceptors' output to our brain. The brain is creating what we see, and, in fact, what we see is not what is actually there, but what the brain interprets from the incoming signals to the eyes. The specifics of our unique color vision are still somewhat of a mystery. However, one thing is clear: the best-known predictors of what sorts of pigments will be expressed by any given animal are the pigments expressed by its nearest living relatives. In our case this means the color red because of the color of our skin - not quite accidentally also bearing a lot of synaesthetics, or as Goethe puts it in his Zur Farbenlehre, a SinnlichSittlich effect, like warm, near, erotic. To an evolutionary biologist this makes a lot of sense, because as primates we developed in our own way in the Mesozoic age, from small rodent-like mammals that were most probably nocturnal and evolving into beings with a unique vision - our tri-receptor color-vision. In this evolution from mammals, segments of color vision were lost, only to be regained for some species of primates, by gene-duplication. Therefore, other mammals, such as dogs and cats, generally only have two-receptor color perception systems, which can distinguish blue and green but not the reds. In other words, we use three types of chemical photoreceptors with red as a new color. This adaptation to see reds is particularly driven by its importance for our survival, since it leads to identification of potential mating partners.

This is one good reason why we love the warm color of light: It affects our limbic system and our deepest emotional instincts, because it supports our survival and wellbeing. It is important to note that it is not the light itself, but rather its effect on the faces we meet or the inventory we see, etc. If we combine (1) the fact that our vision can actually only see the warm colors on a background of daylight with (2) the fact that we have evolved as creatures of light and, even more precisely, as creatures of sunshine, we arrive at an explanation of why the southern culture of light is different from ours: this is simply because in southern cultures the day vision is switched to night vision in a relative short period of time due to their regional environment. When adapted to night vision, all of a sudden the yellow light appears white because of the light-adaption of the eye. This goes for any color of white - cold or warm - since any color in the darkness seems "white." Southern countries are therefore not as dependent on the warm color of light as people tend to be in Scandinavia, 
because they do not have the same long transitions between darkness and light, no background of daylight when they use artificial light.

This is an explanation for why you do not find the warm light when you look at countries nearer to the Equator.

(2) The use of regional lighting conditions: Denmark and Scandinavia have very long transitions between the day and the evening. While near the Equator, the diurnal daylight is followed by the nocturnal darkness in an extremely short period of only 15 minutes all year round; Denmark has a dusk period of approximately $4-7$ hours of the total 24 -hour cycle, with large variations during the year. This being the result of the latitude of $55^{\text {thN }}$ in Denmark, meaning that the sun has to travel a smaller distance compared to near the equator in the same span of time, e.g. 1 hour at the equator equals $1 / 24$ of $40.000 \mathrm{~km}$., while 1 hour at $55^{\text {th }}$ latitude only equals approximately $1 / 24$ of $31.500 \mathrm{~km}$. This, together with the decline of the axis of rotation by 23.5 degrees, explains the differences in the regional rhythms of daylight. Duration of the twilight period between dawn and sunrise varies greatly depending on the observer's latitude - from a few minutes to several hours. At the North Pole there is little or no difference between day and night, while a big difference is observed between summer and winter. Moving to the equator reverses this fact: little if no difference is observed between summer and winter, while a big difference is observed from day to night. In Denmark and Scandinavia this means that electrical lighting during a large part of the day is used on a background of daylight.

This interaction between daylight and electric light has a great impact on the aesthetics. In practice it changes both our perception of light and of color. In Scandinavia, it is impossible to neglect the use of artificial light or neglect the importance of sufficient daylight. We cannot just pour artificial light into the building where there is not enough daylight, and we cannot base lighting on daylight alone. Alvar Aalto is a good example of this pragmatic relationship between daylight and electrical light. Recognizing the beauty and strength of artificial light, though never neglecting the vital daylight, Aalto used daylight in his buildings together with artificial light. He realized that in Scandinavia people cannot live solely on daylight or solely on artificial light. Aalto was one of the first to break with the modernist thoughts of creating an international style, turning away from a pure rational and functional architecture. Working with the local experience and emotions as functions equally important as the more physical functions, Aalto combined daylight and artificial light, working with lightzones, integrating artificial light with the architecture, locating the light in 
the room, and so forth. He understood that light and wellbeing is a result of daylight and artificial light working together, not just replacing each other, but reinforcing each other. Aalto designed several lighting fixtures for his buildings working with the limited amount of regional daylight as an inspiration rather than a limitation.

\section{Conclusion}

The functional approach towards light has not always been the norm - actually it is a rather recent exception to a human-ecological approach - and is derived from the post World War I implementation of technology into our built environment. With electrical lighting dating only 130 years back, its actual influence on our society and on our way of living and thinking is nevertheless enormous and incomprehensible. Before this revolution of light, the sufficient amount of light was measured in candles (candelas), and the perception of brightness was therefore not only a result of the amount of light, but was also dependent on architectural forms and ornaments on doorways and staircases, for example. One could say that this was a culture in which light and form were closely connected. For example, in the "lysedug," a white tablecloth reflects a single candlelight out into the entire room, or the ornamented steps of a stairway lighting up the darkened steps, reducing the possibilities of falling accidents. This location of light in the built environment should be seen in contrast to the dislocation of light mentioned earlier; a dislocation caused by/causing the standardization of light in the 1960s, reducing light into measurable quantities not qualities. In the same perspective, the subsequent method of dealing with Lux should be seen in contrast to dealing with candela/sqm and the perceived brightness of the surfaces in the room.

From an ecological point of view, we need to reduce our energy consumption - in Denmark by 4 percent - which is a new experience. Since we started using electricity, we have only used more and more energy each year. Lighting takes up to 20 percent of our total use of electricity, and to challenge our way of using light is, in this sense, quite necessary if we look into the future. But how do we do this without reducing the wellbeing of the occupants of the built environment?

Much of the explanation to this question can be found in this essay: as described, there seems to be a tendency towards using more and more light in our culture. Taking into consideration that the eye can only see up to 20 different lighting intensities at a time, it is possible to construct a daylight-artificial light environment where these 20 levels are not exceeded, which means that the artificial light responds to a given daylight 

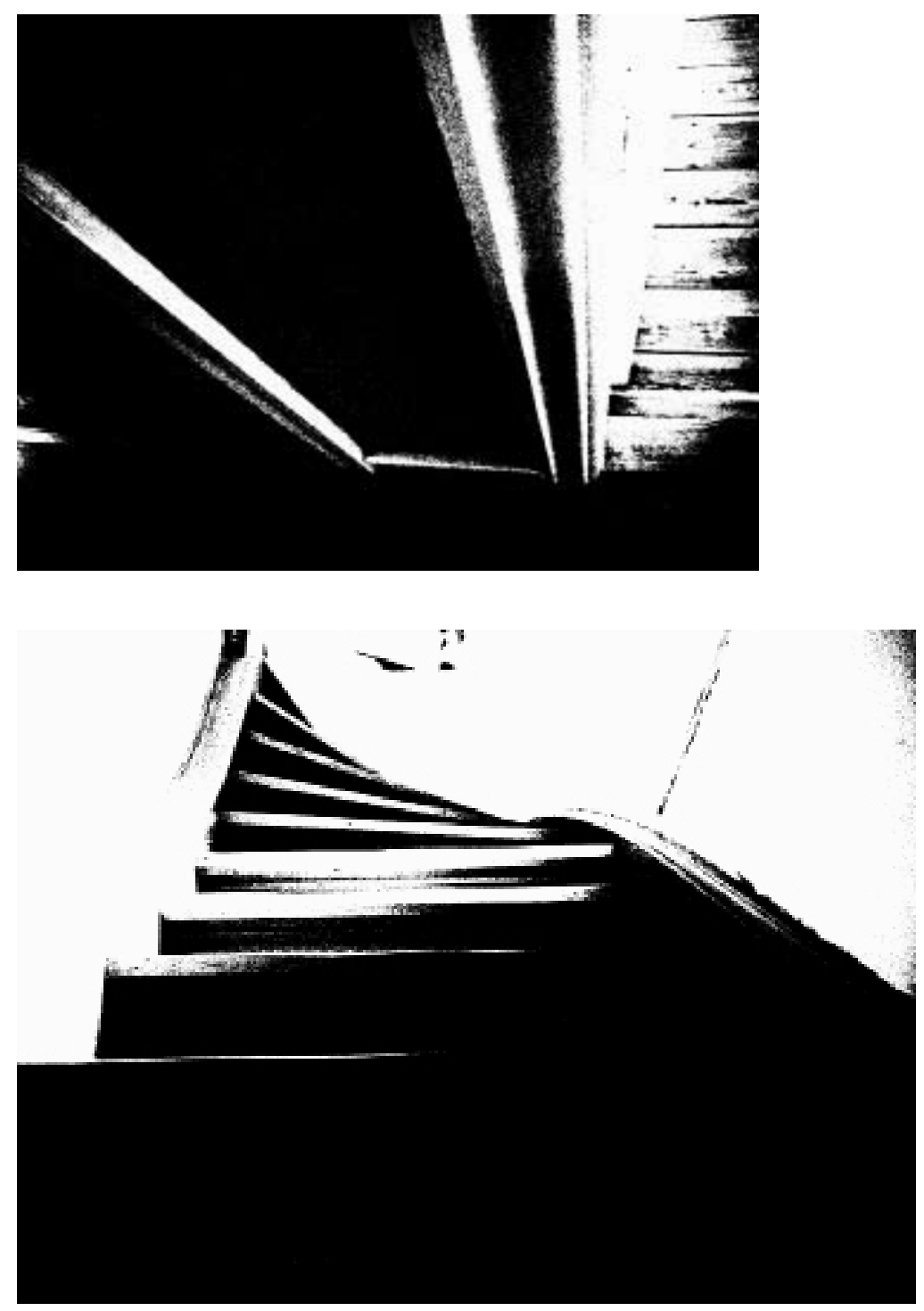

Fig. 1 and 2: Examples of form and light working together, the light being located in the room. In this case, the amount of light is not important in its physical form (Lux) but in its "perceived form" (candela/sqm). Before "the revolution of light," a candle could easily light up these passageways, because they were shaped to our perception. But today even the exceeding use of artificial light cannot prevent elderly people from tripping on a staircase with no perceptual form (top: Stairway and bottom: Doorway). 

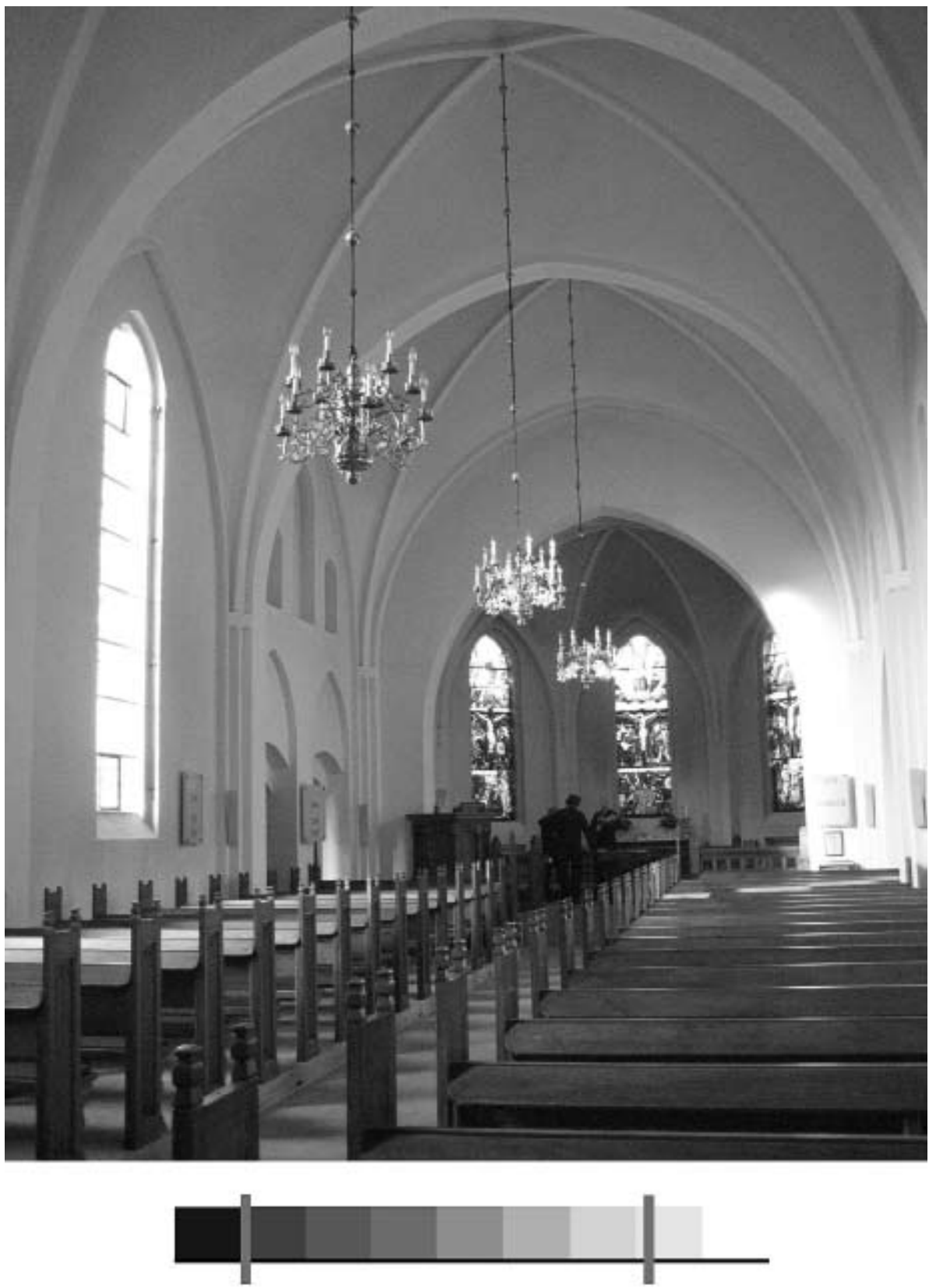

Fig. 3: To locate the light in a room (the brightness) a simple "Scale of light" is introduced. The luminance is not measured in absolutes but in relative significant areas of luminance relating to each other (in 9 visual levels). The scale tells about the character of the room, how the distribution of light is, and where it can be improved. In the case-study shown here the apsis of the church appears too dark in relation to the surrounding space (Lines indicate it is 6 levels darker and that it changes abruptly from $400 \mathrm{~cd} / \mathrm{m}^{2}$ to $5 \mathrm{~cd} / \mathrm{m}^{2}$ ). 
at any time. Daylight is the background determinant/chord for the experienced brightness of artificial light, which means that they both have to be taken into consideration. Again, this explanation speaks against any kind of dislocation of light. Light is related to the daylight of the region and located in a room- not dislocated.

This means that we can abandon any absolute tyranny of Lux and instead work with a more relative, perceived brightness. And in this way we can reduce the amount of electrical light in the evening and use artificial light together with form to avoid exceeding the maximum capacity of light in the eye, when there is daylight. In this way we can regain the darkness at night and yet be able to see and inhabit the large-scale buildings and low roof /deep floor offices that seem to be an inevitable result of our modern urban society.

Overall point of view: Our built environment is, at its best, a reflection of these conditions: location, orientation and activity. Light is one of the important factors that reveals space, time, activity, and focus. Locating light is of great importance in order for this to happen. Our parts of the world were formerly known as places ihibitabilis, meaning that they were not able to house human beings. Along with other new technologies, electrical lighting has made this possible. This mechanization, the lack of sunlight, and the use of electrical light have created a special culture and architecture in the Northern countries - an interaction between daylight and artificial light. In the future we need to focus on a human-ecological lighting and study how light affects us and on how we perceive the light, as humans in a region.

All in all - to relate this to Boehme - this conclusion shows that light is not only out there in physical form or Lux. Light is also a relationship between object/region and subject. In other words, light belongs to the atmosphere.

\section{Notes}

1. Gernot Boehme, Atmosphäre: Essays zur neuen Ästhetik (Frankfurt am Main: Suhrkamp, 1995), $17 \mathrm{~b}$.

2. Sigfried Giedion, Mechanization Takes Command: A Contribution to Anonymous History (Oxford: Oxford University Press, 1948).

3. Paul-Henry Chombart de Lauwe, "Soziologie des Wohnens," Bauen und Wohnen, Vol. 16, no. 6 (1961).

4. See the study "Boligers elforbrugsfordeling på slutanvendelsesgrupper 19462030" carried out by ELFORSK.

5. According to research, this is the case at least in Denmark. 